\title{
APLICACIÓN DE LA POLÍTICA CRIMINAL EN MATERIA DE HOMICIDIO EN CARTAGENA ${ }^{1}$
}

Implementation of the criminal policy in homicide cases in Cartagena

David Sandoval Melendez ${ }^{2}$

Norberto Martínez-De La Hoz

\section{RESUMEN}

En el presente trabajo se abordará la aplicación de la política criminal en la ciudad de Cartagena en materia de homicidio, para a partir de la realización de un análisis determinar si son o no eficaces las políticas criminales en dicho territorio, teniendo como fundamento los datos arrojados COSED (Diagnostico estadístico de delito en Cartagena de indias) que es la entidad encargada de la observación y seguimiento del delito en Cartagena. Con lo anterior, se busca estudiar la problemática, porque de esta manera conoceremos el impacto que ha causado el flagelo del homicidio en la ciudad y en este sentido, podremos conocer las estrategias que se utilizan para mitigar el delito así, se podrán brindar posibles soluciones o sugerencias para contrarrestar el flagelo del homicidio que tiene azotada a la ciudad.

Palabras Claves: Política criminal, Cosed, Crimen Organizado, Sicariato, Pandillas, Criminalística, Criminología, Penología.

\begin{abstract}
In the present work will be addressed the application of criminal policy in the in the city of Cartagena in the matter of homicide, so as to carry out an analysis to determine whether or not the criminal policies in that territory are effective, based on the data provided COSED (Statistical diagnosis of crime in Cartagena de Indias) which is the entity responsible for the observation and monitoring of crime in Cartagena. With the above, we seek to study the problem, because in this way we will know the impact that the scourge of homicide has caused in the city and in this sense, we can know the

\footnotetext{
${ }^{1}$ Articulo resultado del Proceso investigativo Proyecto académico de Trabajo PAT Colectivo IIP-2018, del Programa de Derecho de la Corporación Universitaria Rafael Núñez, campus Cartagena.

${ }^{2}$ Abogado, Docente del Programa de Derecho de la Corporación Universitaria Rafael Núñez, campus Cartagena, orientador del Seminario de Investigación PAT Colectivo de V Semestre II-P2018. E-mail: david.sandoval@curnvirtual.edu.co

${ }^{3}$ Estudiante del Programa de Derecho de la Corporación Universitaria Rafael Núñez, campus Cartagena. E-mail: nmartinezd13@curnvirtual.edu.co
} 
strategies used to mitigate the crime so, possible solutions can be provided or suggestions to counteract the scourge of homicide that has scourged the city.

Key words: Criminal policy, Cosed, Organized crime, Murders, Gangs, Criminalistics, Criminology, Penology.

\section{INTRODUCCIÓN}

La presente investigación tiene como tema principal la aplicación de la política criminal en materia de homicidio, en la cual analizaremos que tan eficaz o no ha sido está en la ciudad de Cartagena. Ésta se hace necesaria para conocer cómo actúa la política criminal de homicidio en la ciudad de Cartagena ya que es de suma importancia que toda la comunidad tenga conocimiento respecto al tema debido a que es un problema presentado constantemente. "La forma cómo se ha planteado la política criminal en el país tiene al menos cuatro grandes errores que la lleva ser incoherente e insuficiente para enfrentar nuestra realidad criminal. Así lo planteó al Gobierno Nacional la Comisión Asesora de Política Criminal, creada en 2011. Entre estos errores se encuentra la Incoherencia, el populismo punitivo, la falta de analizar el contexto y la subordinación a la política de seguridad, Este panorama (Col prensa, 2013, pág .2)”, se debe también a la falta de coordinación entre la propia institucionalidad del Estado y la legislación, lo que nos llevará a cuestionarnos si el Estado está actuando de manera correcta para combatir y prevenir esta problemática.

Para el desarrollo de esta investigación se hizo necesario describir el contexto en el cual se está llevando a cabo, por esta razón son obligatorios unos referentes históricos, para tener conocimiento desde cuando se está desarrollando esta problemática, un referente normativo el cual, nos permitirá conocer las normas, sentencias o decretos que haya expedido la corte, entre otras autoridades competentes, que rijan la política criminal en materia de homicidio. También se hará uso de un marco referencial y uno conceptual para tener conocimiento de opiniones emitidas por expertos en el tema, entender ideas y conceptos que se vean involucrados en la investigación, con el objetivo de comprender con mayor facilidad la misma.

Enfatizaremos el tema de investigación en la ciudad de Cartagena ya que es un sector que se ve bastantemente afectado por la problemática que se está tratando, al tener un índice crítico sobre homicidios nos lleva a pensar sobre la afectación de la política criminal. Por tanto anzalizaremos el motivo por el cual se vive esta situación, conjuntamente examinaremos si el Estado está trabajando en dicho factor y si sus medidas han tenido repercusión alguna, para estos tendremos como base la información emitida por el COSED, entidad encargada de la observación y seguimiento del delito en Cartagena de indias con lo que buscaremos darle mayor veracidad a los resultados obtenidos, por último y no menos importante, resulta interesante comprender las circunstancias que rodean a esta problemática de gran envergadura. 


\section{MATERIALES Y METODOS}

La presente investigación es de carácter jurídico y se realizará mediante el enfoque descriptivo de tipo cualitativo, apoyado de revisión bibliográfica.

Teniendo en cuenta la naturaleza de los objetivos que se han propuesto, será de enfoque descriptivo permitiéndonos analizar, conocer e identificar todo lo relacionado con la política criminal.

Según la recolección de los datos será de tipo cualitativo, ya que los datos que adquiramos nos brindaran unas aproximaciones conceptuales en la descripción del tema de estudio.

Así mismo y de acuerdo a la naturaleza de nuestras fuentes de información, será bibliográfica ya que nuestras unidades de análisis serán documentos escritos por distintos expertos en la temática.

La técnica de recolección de información fue sistemática porque utilizamos fuentes primarias y secundarias como son los materiales bibliográficos existentes ya que, en esta ocasión nos basamos en libros y textos estrictamente jurídicos.

Este trabajo se ha realizado de la siguiente manera, cada uno de los integrantes nos hemos dado la tarea de hacer, un rastreo conceptual para así llenarnos de información jurídica y poder llevar a cabo la investigación.

\section{RESULTADOS Y DISCUSION}

\section{Identificar las herramientas que utiliza la política criminal para mitigar el delito de homici- dio en la ciudad.}

Según lo planteado por Borja (Borja, 2003):

La política criminal lleva inmerso un componente científico, el cual consiste en el estudio de los delitos desde sus formas jurídicas y empíricas, y un componente político con el cual se pretenden llevar a cabo ideas y propósitos concretos. De igual forma como teoría busca desarrollar estrategias para contrarrestar los delitos, pero que este ideal depende de las realidades preexistentes. (p.120)

Las manifestaciones de violencia y delincuencia en la ciudad de Cartagena cada día se hacen más notorias, estas están caracterizadas por presentarse en barrios pobres en los que prevalece el estrato 1 , los actos que se presentan se podrían explicar a partir de dos razones, desde una óptica de criterios económicos en los que prima la necesidad, o se dan desde una perspectiva de violencia intrafamiliar, riñas entre pandillas o riñas personales que se manifiestan como una expresión de la baja valoración de la tolerancia social. 
Cartagena se caracteriza por ser una de las principales imágenes del país para mostrar al exterior por su historia, monumentos, etc, pero la delincuencia, la intolerancia, la falta de educación, hacen que esta ciudad sea cada vez más peligrosa y que conlleve al crecimiento del fenómeno de homicidios cometidos por jóvenes hombres que pertenecen a estrato 1 que carecen de educación.

Como una de las herramientas que se utiliza para hacerle frente al problema, se realiza por parte de la policía metropolitana de Cartagena de Indias, a través de sus unidades de modelo nacional de vigilancia, requisa y control ciudadano, las cuales han permitido mitigar delitos de alto impacto como lo son el homicidio y el hurto a personas.

Por otra parte para reducir este delito la policía se ha tomado varios corregimientos como Santa Catalina, Lomita Arena, Santa Rosa, entre otras en ejecución de un comando situacional, donde todas las especialidades y grupos operativos desplegaron sus capacidades humanas y técnicas en aplicación del proceso de modernización y transformación institucional, que permite estar cerca de los ciudadanos atendiendo sus necesidades de seguridad y convivencia ciudadana, de esta forma, los uniformados dirigen campañas con los ciudadanos encaminadas a prevenir delitos como el homicidio, el hurto, etc., además difunden recomendaciones frente al código nacional de policía y convivencia.

Según el distrito, la ciudad cierra el año con cifras positivamente históricas en lo que ha homicidios se refiere, según las autoridades se han presentado 36 homicidios menos que en el año 2015.

Otra herramienta ha sido el decreto 532 del 2016, que restringe la venta y consumo de licor los días domingo hasta las 10 de la noche y los lunes hasta las 8 de la noche, dicha normativa ha dado buenos resultados en los 40 barrios que se aplica.

Adicionalmente, es prudente mencionar también los controles rigurosos a establecimientos de comercio, vías principales y los planes candado para la seguridad en centros comerciales así como la llegada de 300 nuevos policías que se suman a los 2.200 con los que ya cuenta la capital de Bolívar, como algunas otras de las medidas adaptadas por las autoridades de Cartagena.

Por otra parte con la prohibición de parrilleros en motos, en ciertos barrios de la ciudad, el distrito decidió ampliar por un año más esta medida, la circulación esta restrictiva para barrios como Alto Bosque, Bocagrande, Manga, Laguito, Castillo Grande, Crespo, con la firma del decreto 1511 del 20 de noviembre se busca la conservación del orden público en los barrios mencionados.

De acuerdo a Almanza (Almanza, 2016, pág. 21) "la tasa de mortalidad por homicidio durante el 2014 en el Departamento de Bolívar ha sido de 19,87 por cada 100.000 habitantes. En el 2015, esta 
tasa se ubicaba en 13,69 por cada 100.000 habitantes, consolidándose el departamento de Bolívar como un territorio seguro en la defensa y preservación de la vida de sus habitantes”.

Para terminar el presente objetivo según el centro de observación y seguimiento del delito encontramos que las estrategias o herramientas no fueron eficaces debido a que no disminuyó este fenómeno, ya que en el periodo 2008 y 2017 fue de 2.441 , con un promedio anual del 6\%.

En el año 2017 el mes que menos tuvo homicidios fue enero con 13, y el que tuvo más fue diciembre con 36 homicidios, lo cual indica que las herramientas no están dando resultados y se necesita una política criminal más eficaz para mitigar este delito que tiene azotada a la ciudad. (El Tiempo, 2016. pág 1$)^{4}$

\section{Conocer el impacto que ha tenido el delito de homicidio en nuestra ciudad.}

El centro de información y seguimiento del delito; COSED, presento un diagnóstico al respecto de delitos de homicidio en el año 2015, una actividad que es realizada en compañía de fuentes institucionales del Estado, es decir, fuentes primarias, entre ellas el instituto nacional de medicina legal y ciencias forenses seccional bolívar, el cuerpo técnico de investigación (CTI) de la fiscalía y la policía metropolitana de Cartagena. Se llevó a cabo una comparación de cifras seriadas desde el año 2008 con el objetivo de hacer un análisis acerca del mencionado delito, conforme a los barrios que se encuentran en el perímetro urbano y rural del distrito de Cartagena para determinar el auge y declive del homicidio.

No es un secreto que Cartagena de indias es una ciudad enormemente desigual socialmente, con considerable concentración de ingresos, un mercado laboral informal y con más de mil seiscientos jóvenes que estando en edad de estudiar, se encuentran separados de un plantel educativo, que contribuya al desarrollo personal y profesional, lo que posiblemente los lleva a incurrir en la delincuencia por ejemplo; pandillas, hurtos, entre otras. Generalmente se presentan en barrios marginales de la ciudad, donde la población tiene poca participación en la vida social, económica y cultural debido a la escasez de recursos e insatisfacción de necesidades básicas.

El año 2014 culminó con un total de 295 homicidios, además, se afirma que fue el año con mayor números de homicidio de los últimos 20 años, debido a la intolerancia social expresada en pandillas. Para el 2015 se mostró un comportamiento positivo, bajaron los homicidios en Cartagena un $7 \%$, disminuyó el sicariato, homicidio extorsivo y violencia intrafamiliar con desenlace fatal, debido a políticas y estrategias en la cual el mayor número de casos se presentaron en el barrio Olaya

${ }^{4}$ El Tiempo. Bajaron los homicidios en Cartagena, en 2016, 30 de noviembre 10: 16 Am obtenido http://www.eltiempo.com/colombia/otras-ciudades/bajaron-los-homicidios-en-cartagena-en-2016-43252 
Herrera con un total de 36 casos, luego Nelson mándela con un total de 18 casos y el pozón con un promedio de 17 casos. Sin embargo, sobresalen los barrios como Reposo, Arroz Barato, que reportaron 4 casos cada uno. A pesar de que en 2015 hubo una disminución en homicidios a diferencia con el año 2014, no es suficiente para ubicarse ante otras cifras, por ejemplo, en el 2008 se presentaron alrededor de 171 casos de homicidios, el cual es inferior al índice de homicidios cometidos en el año 2015. En cuanto a los homicidios por edades y sexo de las víctimas período 2008 - 2015, el mayor número de víctimas de homicidios va perfilado al género masculino; jóvenes entre 20 - 25 años y posteriormente el género femenino entre 25 - 29 años de edad. Se logra notar que los homicidios producto de delincuencia organizada son inferiores a los homicidios por violencia interpersonal, lo cual se puede evidenciar la intolerancia como principal rasgo distintivo.

Por otra parte los homicidios de delitos sexuales, se presentan en barrios vulnerables, carentes de condiciones sociales y económicas, los barrios que encabezan la lista del 2015 son Olaya Herrera y el Pozón, son los sectores donde se presenta con mayor frecuencia, seguido de otros como Nelson Mándela, San Fernando, La Boquilla, San José de los Campanos, La María. Las víctimas de estos delitos son en su mayoría niñas menores de edad de 14 años e infantes de $0-4$ y de $5-9$. A diferencia de los homicidios, los casos de delitos sexuales se distribuyen mayormente en víctimas de sexo femenino, pero también con evidencias de casos en los que la víctima termina siendo del sexo contrario, sobre todo con la particularidad de pertenecer de los 5 a los 9 años de edad. En cuanto al perfil del agresor, se identifica a los conocidos como el principal perpetuador de este tipo de delito, seguido por familiares, (cualquier miembro con grado de consanguinidad cercano y conviviente del mismo hogar donde reside la víctima), el agresor dudoso o desconocido con el tercer lugar de importancia y en adelante se identifican como la pareja o ex pareja de la víctima, miembros de pandillas o delincuencia común y hasta miembros de las fuerzas públicas. (COSED Alcaldia Mayor De Cartagena De Indias, 2017). ${ }^{5}$

Según los expuesto anteriormente por COSED se puede observar cual ha sido el impacto que ha causado el delito de homicidio en la ciudad de Cartagena, nos hemos detenido a observar su evolución y nos encontramos con dos puntos fundamentales, el primero referente a que la inestabilidad desbordada en el delito de homicidio se puede lograr comprender que desde el año 2006 se intentó aplicar cierta política criminal, lo cual tuvo un buen resultado aunque no fueron las políticas más idóneas y solo después de 2 años se lograron ver los resultados es decir en el año 2008 se logra tener una tasa de 171 homicidio lo que significa que la cuidad de Cartagena una vez más se mantuvo entre las tasas más altas de homicidio, sin preveer que en los años venideros sería peor, realizado

${ }^{5}$ COSED Alcaldía mayor de Cartagena (2017) aporto los porcentajes de homicidio ejecutado en los barrios de Cartagena. Obtenido en http://www. cosed.org/a/wp-content/uploads/2016/07/Diagnosticofinal.pdf 
un breve paralelo entre 2008-2014 se puede ver el aumento progresivo de homicidio, lo cual nos lleva a tener la tasa más alta de los últimos 20 años con un porcentaje de 295 homicidios. De lo ya expuesto se puede observar como el Estado ha sido incapaz de crear políticas criminales que contrarresten el delito de homicidio, lo que significa que el Estado de una u otra formas está vulnerando el derecho a la vida establecido en nuestra constitución en su artículo 11, pero de una forma indirecta ya que no está generando una política criminal eficaz para combatir la criminalidad (omisión), esto ha generado un impacto negativo en la ciudad de Cartagena y le ha arrebatado a infinidades de familias seres queridos. Ha sido negativo este impacto porque Cartagena sea convertido en una ciudad insegura donde se vulneran derechos por distintas razones o bajo modalidades como lo es el crimen organizado, riñas, hurtos etc.

El segundo aspecto ha sido el aumento del desempleo lo que ha obligado algunas personas a desempeñarse en actividades ilegales, estos manifiestan que deben llevar el sustento diario a sus familias razón por la cual se puede presentar la criminalidad, (pero siendo conscientes y colocándonos en sus zapatos ¿Que haría usted al padecer condiciones precarias donde carece de lo básico para subsistir en este Estado injusto y desigual? Es difícil padecer un estado igual o similar pero no se puede justificar la criminalidad por ningún motivo, lo razonable sería solicitarle al estado mediante una petición un empleo digno e inclusive si es necesario utilizar una huelga pacifica donde sea posible ser escuchado para acceder a un empleo digno, aunque existen muchos programas o seguros donde el Estado le da subsidios a las personas desempleadas para subsistir) se puede notar que debido a la carencia de empleo, de educación y oportunidad el ciudadano se ve en la penosa necesidad de delinquitr, lo que de una u otra forma tiene un resultado grave pues implica arrebatarle la vida a otras personas, entonces, lo ya expuesto nos conduce a vivir en una ciudad sumergida en el miedo debido a la falta de política criminal.

\section{Sugerir posibles soluciones aplicables en materia de política criminal para mitigar el delito de homicidio}

Teniendo presente los argumentos presentado por Pérez Pinzón quien concibe que la política criminal es "el conjunto de mecanismos e instrumentos con que cuenta el aparato estatal, en orden a combatir la criminalidad (Arrubla, 1999, pág. 75)”

El delito de homicidio en Cartagena, ha sido un flagelo que ha impactado negativamente a la ciudad, so pena sea incrementado la inseguridad en las distintas localidades de la cuidad. En el transcurso de la investigación ha sido factible observar que en los últimos 3 años el homicidio sea incrementado. Según lo expuesto anteriormente la tasa de homicidio en el año 2016 fue 239 homicidios y en el año 2017 de 249,(El universal, 2018. pág1) ${ }^{6}$ de igual forma se logró

${ }^{6}$ El Universal Cartagena. 249 asesinatos se registraron en Cartagena durante 2017. 02 de enero de 2018, 06:48 pm, Obtenido http://www.eluniversal.com.co/sucesos/249-asesinatos-se-registraron-en-cartagena-durante-2017-269230 
conocer en su mayoría las razones de por qué el delito de homicidio posee altas cifras en la ciudad de Cartagena, las principales razones son la desigualdad social, la falta de oportunidades, riñas, venganza personal y pasional y sicariato, lo anterior es el resultado de la carencia de trabajo digno, educación de calidad y por último el desinterés que poseen los jóvenes de la cuidad que se manifiesta no asistiendo a los poco planteles educativos que existen y por ende quedan sujetos en su mayoría a utilizar el tiempo en actividades ilegales, consideramos que para muchos de estos jóvenes, la rentabilidad de las actividades criminales es mayor que los beneficios de una actividad legal. Y encima de estas vulnerabilidades, tenemos la presencia del crimen organizado y el tráfico de drogas. Queremos ser claros: América Latina ha sido un continente violento desde hace muchas décadas, incluso antes de la irrupción de los carteles de drogas, pero no cabe duda que la presencia del narcotráfico fortalece la violencia, estimamos que un 30\% de los homicidios se debe al crimen organizado.

Finalmente, para empeorar las cosas, lo que debería ser una solución se vuelve una causa de mayor crimen y violencia: el accionar de nuestros sistemas penitenciarios. Es factible ver que las pandillas adquieren fuerza en las cárceles, donde actúan sin ninguna limitación judicial, esto se da debido que en su colectividad éstas imparten orden en las cárceles, estos eventos son los que le dan el dominio a las grandes bandas delincuenciales y al culminar su condena plasman nuevas organizaciones criminales que se ve manifestadas en las calles de la ciudad de Cartagena. Se logra observar que las cárceles son obsoletas esto se puede expresar debido a que no se ha está cumpliendo las funciones de la pena establecida en el ordenamiento penal colombiano en su artículo 5 , se puede captar a simple vista la carencia de rehabilitación y reinserción de los individuos a la sociedad, la vulneración de los principios expuestos en dicho artículo que sin duda ha llevado a un robustecimiento de la cultura criminal, a causa de esta triste realidad, como grupo de PAT se ha intentado sugerir posibles soluciones a esta problemática.

Cabe resaltar que no existen recetas mágicas para resolver ningún problema complejo, pero, el conjunto de medidas que aquí se enumera, ha dado buenos resultados en otros factores y esperamos que de una u otra manera ayuden a disminuir o combatir el delito de homicidio:

1.- Inclusión Juvenil. Se trata de una situación de desigualdad fáctica que se resiste a las políticas públicas. La desigualdad genera violencia y esto explica, parcialmente, que la mayor parte de las muertes violentas ocurra entre los sectores más vulnerables o más abandonados.

2.- Reforma Policial. Muchas organizaciones criminales tienen a policías y ex -policías como líderes. Se trata de bandas dedicadas al secuestro, extorsión, tráfico de armas y municiones y protección de cadenas de comercialización de droga. 
3.- Desarme. Gran número de los homicidios se ejecutan con armas de fuego. Urge ejecutar, eficazmente, las medidas previstas en la ley para el desarme, control de armas y municiones.

4.- Reforma legislativa garantista. Las cárceles no sirven para "regenerar" a nadie. La inmensa mayoría de los presos son jóvenes pobres que están en detención preventiva (es decir, no sabemos si son responsables de lo que se les imputa), investigados por delitos mínimos (entre ellos posesión de pequeñas cantidades de drogas). Tener más presos no sirve para reducir los delitos violentos, pero sí para iniciar o profundizar en trayectos delictivos de vida. Es decir, la cárcel aumenta la violencia, resulta necesaria, por tanto, una reforma legislativa garantista que priorice la libertad por sobre la prisión y que reduzca las penas en materia de pequeños delitos (como el microtráfico).

5.- Políticas Locales de Convivencia. La violencia no es igual en todos lados, los pobres la viven de manera cuantitativa y cualitativamente más drástica. Algunos barrios tienen tasas superiores a los 100 homicidios por cada 100 mil habitantes. Es necesario frente a ello impulsar, en territorios priorizados, políticas locales de convivencia, con los siguientes ejes: contraloría social de la función policial, inclusión y protagonismo juvenil e infantil, prevención de violencia de género, resolución social de conflictos, reconversión de las economías del microtráfico y negociación pacificadora con bandas juveniles.

6.- Eficacia Policial. Pero ninguna política local de convivencia tendrá éxito sostenido si no existe un trabajo policial eficaz sobre los territorios priorizados, que evite que las organizaciones criminales más consolidadas (dedicados a la gran venta de droga, el secuestro, el robo de vehículos, etc.) saboteen el trabajo preventivo y de empoderamiento popular para la convivencia.

\section{CONCLUSIONES.}

Teniendo en cuenta lo planteado en la presente investigación analizamos cada detalle, y nos encontramos con resultados ineficaces, es decir, la aplicación de la política criminal en materia de homicidio no es la más óptima debido a que no se ha podido combatir la criminalidad, teniendo presente el diagnostico presentado por COSED no permite observar un impacto negativo por tal razón se puede ratificar que Cartagena es una ciudad con una grave desigual social, so pena de jóvenes que deberían encontrarse en planteles educativos adquiriendo formación intelectual y ética, lo que traería como resultado el auge de la ciudad pero lamentablemente se encuentra todo lo contrario a lo expuesto debido a que la carencia de oportunidades conduce a muchos jóvenes a actuar por la ignorancia y no dejando perspectiva para razonar y poder darle una solución profesional a los conflictos que ha diarios nos aquejan, se puede manifestar que la carencia de formación académica de muchos jóvenes es la que ha producido o generado una ciudad insegura 
Realizando un paralelo entre el año 2008 y 2016 es factible notar las variaciones en tasas, factores y la razón producto del homicidio, se puede ver que a pasar que el año 2006 las tasas más altas por homicidio fueron el resultado del sicariato y las pandillas, pero la implementación de política criminal logroó disminuir y se puedo combatir este fenómeno dando dos años más tarde un buen resultado, sin embargo, en la actualidad los crímenes comente en su mayoría por el crimen organizado o bandas criminales, disputas interpersonales y por ultimo discusiones entre parejas y ex parejas que terminan por arrojar la muerte de personas que fueron víctimas de un agresor demediado y celoso, del anterior análisis se puede comprender que la aplicación de la política criminal en la ciudad ha sido ineficaz razón por la cual se presenta a diario homicidios que son cometidos en las distintas localidades de la ciudad, ellos ha generado un impacto social negativo debido que se carece de eficaz política criminal, razón de este argumento se da por el aumento que se ha dado en la última década en Cartagena, se puede ver cómo en el año 2008 la tasa de homicidio fue 171 , en comparación del 2016 donde se da una tasa de 239 casos, que en su mayoría pertenecieron al sexo femenino. Esto ha propiciado un estado de miedo en los ciudadanos debido que se teme a la pérdida de la vida y de los bienes materiales, por lo tanto los ciudadanos optan por dejar sus pertenencias en sus hogares, para no ser víctimas de estos sucesos que en su mayoría terminan vulnerando el derecho a la vida.

\section{REFERENCIAS BIBLIOGRÁFICAS:}

Almanza Agámez, C. (2016), Análisis de muertes por causas externas en el departamento de Bolívar: Enero - diciembre 2011-2015. Revista Jurídica Mario Alario D’Filippo, 8 (16): 12-37. Recuperado de DOI: https://doi.org/10.32997/2256-2796-vol.8-num.16-2016-1530

Molina Arrubla, C. (1999). Introducción a la criminología, Bogotá, Colombia, Ed. Editorial Leyer.

Emiliano Borja Jiménez, Sobre el concepto de política criminal. Una aproximación a su significado desde la obra de Claus Roxin, Anuario de Derecho Penal y Ciencias Penales, enero de 2003, At. 113.

Cosed. Alcaldia Mayor De Cartagena De Indias. Aportando los porcentajes de homicidios ejecutados en los barrios de Cartagena (2007).

Redacción E1 Tiempo. Bajaron los homicidios en Cartagena, en 2016. El Tiempo. 30 de noviembre de 2016. At. Al.

Hylenne Guzmán Anaya. 249 asesinatos se registraron en Cartagena durante 2017. El Universal 
Cartagena. 02 de enero de 2018. At. Al.

Colprensa. Comisión dice que política criminal del país es insuficiente. El País. 20 de diciembre de 2013. At. Al. 